John Whitman

Department of Linguistics

Cornell University
Prepublication version. Published in G. Cinque and R. Kayne (eds.) Handbook of Syntactic Variation. Oxford, Oxford University Press, 880-902.

\title{
Preverbal Elements in Korean and Japanese
}

\subsection{Pre- and post-verbal negation in OV languages.}

Dahl (1979) (see also Dryer 1988, 1992) observes that SOV languages evince two typical negation patterns: one where the marker of negation immediately precedes the verb, and one where it follows. Inflected negative markers appear in the latter pattern; preverbal negators are uninflected particles. These two patterns are shown in (1-2) with examples from Korean and Japanese.

\section{(1) Preverbal Negation}

a. Mica ka hakkyo ey an ka-ss-ta. (Korean)

Mica NOM school to NEG go-PAST-INDIC

'Mica didn't go to school.'

b. Tuki na mi-tama $\Phi-\mathrm{i}$ so! (Japanese; Taketori Monogatari 859)

moon NEG see-HONORIFIC-CONTINUATIVE PRT

'Please don't look at the moon!'

\section{(2) Postverbal Negation}

a. Mica ka hakkyo ey ka-ci anh-ass-ta.(Korean)

Mica NOM school to go-SUSP NEG-PAST-INDIC

'Mica didn't go to school.'

b. Yooko ga gakkoo ni ik-ana-katta koto (Japanese)

Yôko NOMschool to go-NEG-PAST that

'that Yôko didn't go to school.' 
The preverbal negation pattern in (1b) is limited to negative imperatives in Old and Early Middle Japanese $\left(8^{\text {th }}-12^{\text {th }}\right.$ c. $)$. Dryer $(1988,1992)$ shows that the SONegV pattern in (1a) and the SOVNeg pattern in (1b) are overwhelmingly the most common patterns in verb-final languages. 39 (15 families) of the 117 verb-final languages in Dryer's (1988) sample show SONegV, while 64 (19 families) show SOVNeg. In contrast, 8 languages (5 families) have NegSOV, while 6 (3 families) have SNegOV (1988: 96).

There is an obvious parallel between the uninflected negative particle in the SONegV pattern and nonhead negators such as French pas. At the same time, there is a parallel between the postverbal negators in the SOVNeg pattern, which may be inflected, and head-type negators such as French ne. For a concrete comparison, let us consider Pollock's (1989: 414) analysis of French negation. The nonhead negator pas occupies the specifier position of a projection above VP, while ne originates as the head of this projection. Pas has the properties of a maximal projection: it does not block movement of the verb. Ne is analyzed by Pollock as a clitic, which moves with the verb to Tense.

(3) [тр Paul [ $\mathrm{T}^{\prime}$ ne mange $\left[\mathrm{Negp}\right.$ pas $\left.\left.t_{\mathrm{ne}}\left[\begin{array}{ll}\mathrm{vp} & \mathrm{t}_{\mathrm{V}}\end{array}\right]\right]\right]$.

"Paul doesn't eat."

Like ne, the post verbal negators anh- (2a) and -ana- (2b) are heads. Korean anh-is inflected for tense and selects a verbal complement in suspective $-c i$. It may optionally assign overt case to this complement (Song 1971):

(4) Mica ka hakkyo ey ka-ci lul anh-ass-ta.

Mica NOM school to go-SUSP ACC NEG-PAST-INDIC

'Mica didn't go to school.'

Japanese - ana- also inflects for tense and shares the adjectival inflectional pattern of the independent negative adjective $n a-(i)$ 'not exist'.

In a standard left-branching analysis of Korean or Japanese clause structure, these parallels are difficult to capture. Postverbal negators in the SOVNeg pattern may be straightforwardly analyzed as heads (see Park 1990, Ahn 1991, and Choi 1991 for head analyses of postverbal negation in Korean). But preverbal 
negators in the SONegV pattern may not be analyzed as specifiers. ${ }^{1}$ In a base-generated analysis of verbfinal word order in an SONegV sentence like (1a), for example, the negative particle an must be analyzed as sister to the verb, in the position of a complement, not a head. ${ }^{2}$

(5) $(=1 \mathrm{a})$

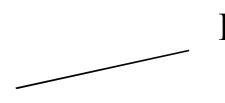

DP

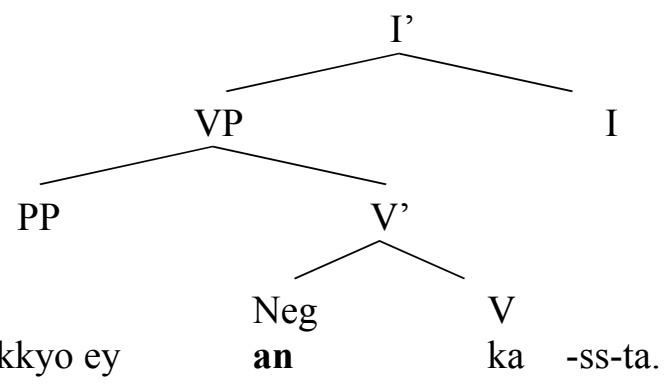

Mica NOM school to NEG go -PAST-INDIC

'Mica didn't go to school.'

The analysis in (5) fails to explain how it is possible for the negative particle to be realized as a complement of $\mathrm{V}$, a position normally reserved for arguments. But more directly to the current point, it fails to capture the parallelism between preverbal negators in the $\mathrm{SONegV}$ pattern and uninflected negative particles like pas in VO languages.

This parallelism can be captured under the account of Object - Verb - Infl order in Kayne (1994, §5.5), according to which head final order is derived by movement of VP to the left. ${ }^{3}$ Under this approach,

${ }^{1}$ In an ingenious analysis, Lee (1992) analyzes preverbal an in Korean as a right-branching specifier. The surface order in (1a) is then derived by movement of the lexical verb rightward over an. The chief difficulty with Lee's analysis is the lack of independent evidence for specifiers on the right, in Korean or other languages. But in important ways his analysis anticipates the antisymmetric analysis of Korean negation. 2 Sells (1998) explicitly analyzes preverbal an as a complement.

3 The implications of Kayne's proposal for Dahl and Dryer's typological generalizations are pointed out by Whitman 1995, 2000, which implements an analysis of Korean negation based on the specific proposal in 
uninflected negative particles in the $\mathrm{SONegV}$ pattern of (1a) are generated in the specifier of a projection which selects VP as its complement, parallel to pas in the specifier of $\mathrm{NegP}$ in (3).

(6) $(=1 \mathrm{a})$

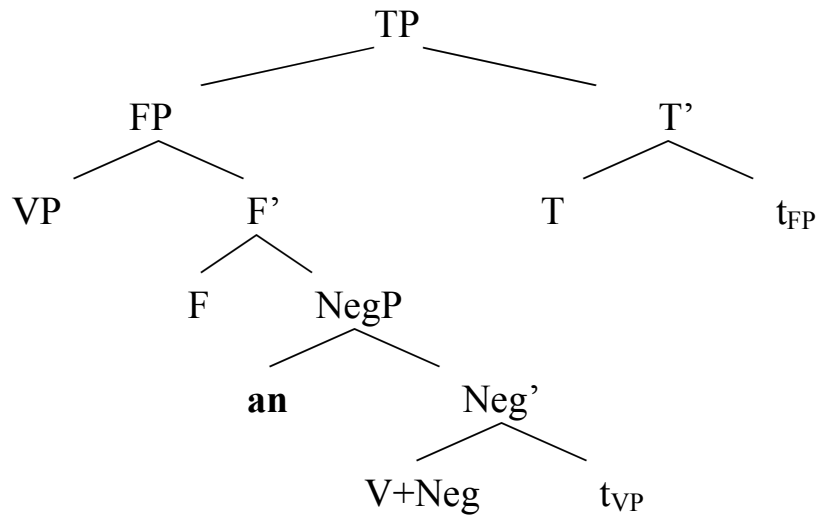
[Mica ka hakkyo ey $\mathrm{t}_{\mathrm{v}}$ ]
ka-
-ss-ta.
Mica NOM school to
NEG go
-PAST-INDIC

The verb first raises to the head of NegP. The remnant VP then moves past the negative particle an into the specifier of a higher projection, ${ }^{4} \mathrm{FP}$ in (6); FP then moves to the specifier of TP. ${ }^{5}$

Kayne 5.5, footnote 14. See Hagstrom (2000) as well for a different leftward phrasal movement analysis of Korean negation and Cinque (1999) for a leftward VP movement analysis of the postverbal negative modal mos. A modification of Cinque's analysis of mos will be presented below.

4 I assume that movement past an in the specifier of NegP is possible for the same reason that phrasal movement past "adverbial" specifiers is generally possible: the fronted VP and the negative element differ with respect to some crucial feature, thus avoiding a Relativized Minimality violation. See Cinque (1999) for relevant discussion.

5 As Kayne (1994: 141, footnote 14) notes, head-final languages such as Korean and Japanese must contain some projection with a non-final head to host, e.g. subjects and topics, if these are to c-command the rest of the clause. Whitman $(1998,2001)$, adopting a suggestion of Kayne's, argues that the nominative markers $i / k a$ (Korean) and $g a$ (Japanese), head the projections hosting subjects in their surface position. On this view the surface representation of (6) is as follows: 
In the Korean SOVNeg pattern in (2a), the negative head anh- is generated in NegP; the complement of NegP, containing the lexical verb suffixed with $-c i$, moves beyond Neg. ${ }^{6}$ Finally the entire NegP moves to the specifier of TP.

(7) $(=2 a)$

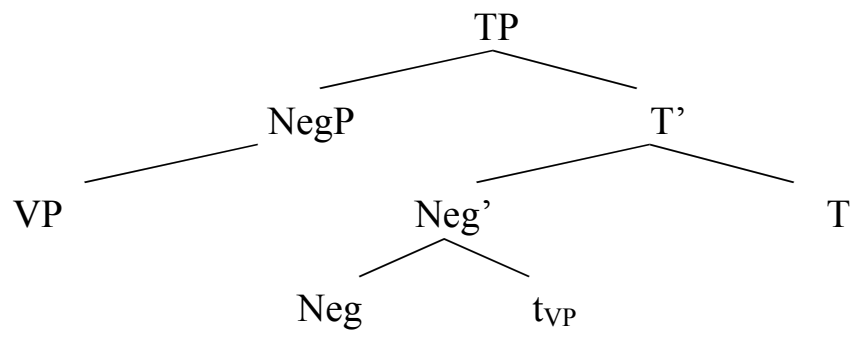

$\begin{array}{ll}\text { Mica ka hakkyo ey ka-ci anh } & \text {-ass-ta. } \\ \text { Mica NOM school to go-susp NEG } & \text {-PAST-INDIC }\end{array}$

The Japanese SOVNeg pattern in (2b) represents a variation on this basic derivation, where the head of Neg is the bound suffix -ana-. In Japanese the lexical verb raises and adjoins to Neg; the rest of the derivation is as in (7).

(8) $(=2 b) \quad$ [тр [vp Yooko ga gakkoo ni $\left.t_{\mathrm{V}}\right]$ [Negp ik-ana- $\left.\mathrm{t}_{\mathrm{VP}}\right]$-katta] koto

Yôko NOM school to go-NEG- $\quad$-PAST that

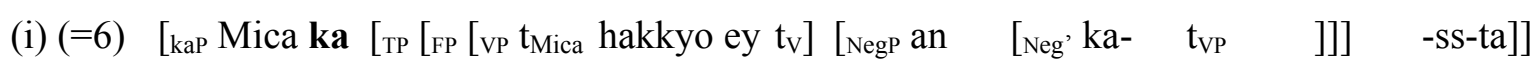
$\begin{array}{llll}\text { Mica NOM } & \text { school to } & \text { NEG } & \text { go- }\end{array}$

'Mica didn't go to school.'

The phrasal projection kaP in (i) may be identified as an Agreement projection, or perhaps the Finiteness Phrase of Rizzi (1997).

6 In (7) I have shown Spec, Neg as the landing cite of the complement of $\mathrm{Neg}^{0}$, and labeled this projection VP for simplicity. But the fact that the complement of $\mathrm{Neg}^{0}$ takes the supective suffix $-c i$ and may be case marked, as we saw in (4), suggest that VP-ci has nominal properties, as first pointed out by Song (1971). One possibility is that VP-ci moves on to the specifier of projection where accusative (and in certain instances, nominative) case is assigned. 
'that Yôko didn't go to school.'

A final pattern of variation is presented by the Korean negative potential particle mos 'cannot'. Mos appears in a preverbal pattern parallel to (6) as well as a postverbal pattern:

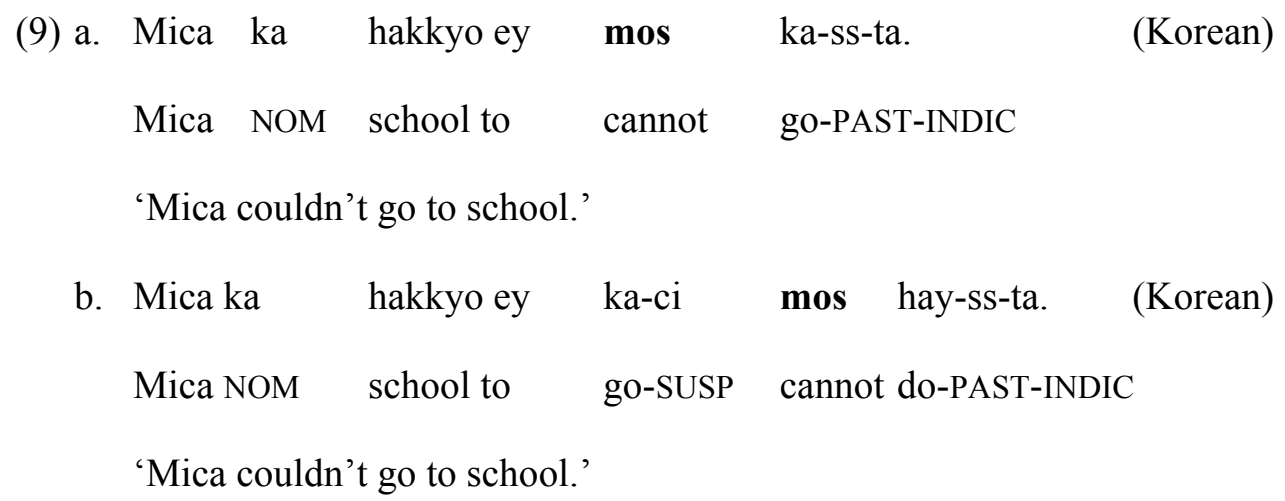

The preverbal pattern in (9a) can be derived in the same way as (6): the lexical verb raises to the head of the projection hosting mos, and the remainder of the VP moves over mos in Spec, NegP. Cinque (1999) suggests a derivation for the postverbal pattern in (9b) where mos occupies the head of a modal projection; mos blocks raising of the lexical verb to $\mathrm{T}$, which must therefore be supported by insertion of dummy $h a-$ 'do'.

The occurrence of mos in the preverbal pattern (9a) and the parallelism with negative an and anhsuggests a slightly different approach. Suppose that $m o s$, like $a n$, is uniformly a specifier. ${ }^{7}$ The heads of the projections hosting mos and an optionally select a lexical verb suffixed with supective $-c i$. The form $\mathrm{V}-c i$ is ineligible for head raising, perhaps due to its nominal character (cf. Song 1971). Thus the only licit derivation when $\mathrm{V}-c i$ is selected is to move the entire projection containing $\mathrm{V}$-ci to the left of mos or an. In the case of anh- (7) a lexical head of NegP is available to support Tense, but mos occurs with no lexical head of its projection; thus dummy $h a$ - 'do' is inserted, as Cinque proposes.

7 J.-H. Lee (1992) also analyzes mos, together with preverbal an, as specifiers. 
The co-occurrence possibilities of an and mos confirm that these items occupy distinct projections and indicate that an is in a higher projection than $\operatorname{mos}^{8}$ Of the four combinations in (10), only the pattern in (d) is acceptable (albeit awkward) to most speakers.
a. *Mica ka hakkyo ey mos an ka-ss-ta.
Mica NOM school to cannot NEG go-PAST-INDIC
b. ${ }^{*}$ Mica ka hakkyo ey an mos ka-ss-ta.
Mica NOM school to NEG cannot go-PAST-INDIC
c. *Mica ka hakkyo ey an ka-ci mos hay-ss-ta.
Mica NOM school to NEG go-SUSP cannot do-PAST-INDIC
d. ?Mica ka hakkyo ey mos ka-ci anh-a-ss-ta.
Mica NOM school to cannot go-SUSP NEG-PAST-INDIC
'It is not the case that Mica couldn't go to school.'

(10d) is derivable on the assumption that the projection including mos is selected by negative anh-. Within that projection, preverbal mos is derived as in (9a); the projection containing mos is then fronted to the left of anh- as in (7). (10a) and (10c) can be ruled out on the assumption that the underlying order of an and mos is fixed: the projection containing mos does not select the NegP projection containing an.

Particularly interesting is the unacceptability of (10b). We might expect this pattern to be derivable from the same basic order of negative elements as (10d), that is, an... mos, by successive cyclic verb raising to $\mathrm{T}$, followed by fronting of the remnant projection to Spec, TP. This is shown in (11):
(11) $(=10 b)$
*[Tp [Fp [VP M
Mica NOM school to
$\left.\left.\left[\operatorname{ModP} \operatorname{mos} t_{V} t_{V P}\right]\right]\right]$
ka-ss-ta]
NEG-
cannot
] $\left[\mathrm{NegP}\right.$ an $t_{\mathrm{V}}$
go-PAST-INDIC

\footnotetext{
8 This indicates that $m o s$ is located in a projection corresponding to Cinque's Mod $_{\text {possibility }}$, under Tense and negation, rather than a higher modal projection.
} 
In (11), the verb - $k a$ - 'go' raises first to the head of ModP, then through the head of NegP to adjoin to T. Meanwhile the remant VP moves past mos and an to the specifier of FP, as in (6). Finally FP moves to Spec, TP. Such a derivation would depend crucially on the ability of the verb to move though NegP, ModP, and other intermediate projections to adjoin to $\mathrm{T}$, a potential derivation for $\mathrm{S}-\mathrm{O}-\mathrm{V}-\mathrm{Tense}$ order mentioned by Kayne (1994, §5.5, footnote 14). We have seen evidence in this section that verb movement to the left does occur in Korean and Japanese, specifically in the derivation of the SONegV pattern. But the unacceptability of (10b) indicates that the verb and Tense suffixes are not composed by head movement and adjunction of the former to the latter. Instead, composition of the verb and Tense affixes is the result of what Kayne calls "pure agglutination": fronting of the projection containing the verb to the specifier of $\mathrm{T}$, followed by a postsyntactic operation that converts the verb and tense suffixes into a single phonological word. ${ }^{9}$ This conclusion, combined with the assumption that an occupies a position structurally higher than mos, accounts for the co-occurrence patterns of these two negators in (11).

Summing up our discussion so far, we have seen that under the antisymmetric account, the SONegV pattern corresponds to the configuration with negator in Spec, like French pas. The SOVNeg pattern corresponds to the configuration with a negator in head position. This configuration may either block raising of the lexical verb if the negator is a free morpheme, as in the Korean pattern (7), or host the raised verb if the negator is a bound morpheme, as in the Japanese negation pattern (8).

The basic analysis where negation may be realized either as a specifier or head predicts in principle that there may be two negative morphemes, one in each position. Although neither Japanese nor Korean evinces such a pattern, it occurs in Burmese, a Sino-Tibetan OV language. As predicted by the antisymmetric

\footnotetext{
9 Sakai (1998) argues that verbal affixes in Japanese are composed postsyntactically with the verb by the oepration of Morphological Merger (Halle \& Marantz 1993). While Sakai's conclusion seems correct for the particular case of tense suffixes discussed in this section, we have seen that a stronger conclusion - that Korean and Japanese lack verb movement altogether - is not supported.
} 
analysis, the preverbal negative particle in Burmese is in immediate preverbal position. The postverbal negative suffix immediately follows the verb and precedes discourse modal suffixes:
a. K'inbya ma thwà bù là.
(Burmese)
you NEG goNEG Q
'Are you not going?"
b. Diné ma thwà néh.
today NEG goNEG.IMPERATIVE
'Don't go today.'

The Burmese pattern is naturally analyzed with the negative particle $m a$ in the specifier of NegP, and the negative suffix (matrix nonimperative $b u$, negative imperative néh) in the head of NegP. Derivation of (12ab) proceeds as in (8): the verb raises and adjoins to the negative heads bù or néh.

Thus far in this section I have shown that an antisymmetric analysis of SOV negation can account for the following facts:

- OV languages attest both preverbal and postverbal negation.

- Preverbal negators are typically immediately preverbal.

- Preverbal negators are always uninflected.

- Postverbal negators may be inflected.

- OV languages may have "bipartite" negation; when they do, the preverbal negator is immediately preverbal and uninflected.

I have also shown that the preverbal SONegV pattern is not straightforwardly accounted for under base generated left branching (symmetric) analysis. In the remainder of the section I will adduce further evidence from Korean and Japanese for the antisymmetric analysis of OV negation.

\subsection{Preverbal negation in Korean periphrastic causatives}


Bratt (1993), citing Lee (1988) and Sells \& Cho (1991/2000), observes that Korean periphrastic causatives are ambiguous when the preverbal negative particle an precedes the embedded verb and the causee argument is marked with accusative case. ${ }^{10}$

Emeni kkeyse ttal ul an mek-key ha-si-ess-ta. (Bratt 1993:245)

mother NOM daughter ACC NEG eat-COMP do-HON-PAST-INDIC

'The mother made the daughter not eat.' OR

'The mother didn't make the daughter eat.'

This ambiguity disappears when the causee is marked nominative:

Emeni kkeyse ttal i

an mek-key ha-si-ess-ta. (Bratt 1993:245)

mother NOM daughter NOM NEG eat-COMP do-HON-PAST-INDIC

'The mother made the daughter not eat.'

The ambiguity in (13) can be explained by two distinct derivations. In the derivation in (15) below, the complement of the matrix causative verb ha- (labeled CP in (15)) contains the negative specifier an, which therefore takes embedded scope. Word order internal to the complement is derived as in (6), by raising the embedded verb to Neg and raising the remnant VP past an. The entire complement clause then raises past the matrix causative verb $h a-$.

(15) Emeni kkeyse $\left[\mathrm{CP}\left[\mathrm{vP}\right.\right.$ ttal ul $\left.\mathrm{t}_{\mathrm{V}}\right]$ an mek-key $\left.\left.\mathrm{t}_{\mathrm{VP}}\right]\right]$ ha- $\mathrm{t}_{\mathrm{CP}}$.

Mother NOM daughter ACC NEG eat-COMP do

'The mother made the daughter not eat.'

10 Not all speakers accept this ambiguity. Some speakers report only an embedded scope interpretation for (13). Such speakers presumably disallow raising of the embedded verb suffixed with $-k e y$. 
In the derivation in (16), the negative specifier an is in the matrix clause and therefore takes scope over the matrix causative verb. This derivation proceeds as in (15), except that following raising of the complement $\mathrm{CP}$, the embedded verb (suffixed with $-k e y$ ) raises on and adjoins to causative $h a$-.

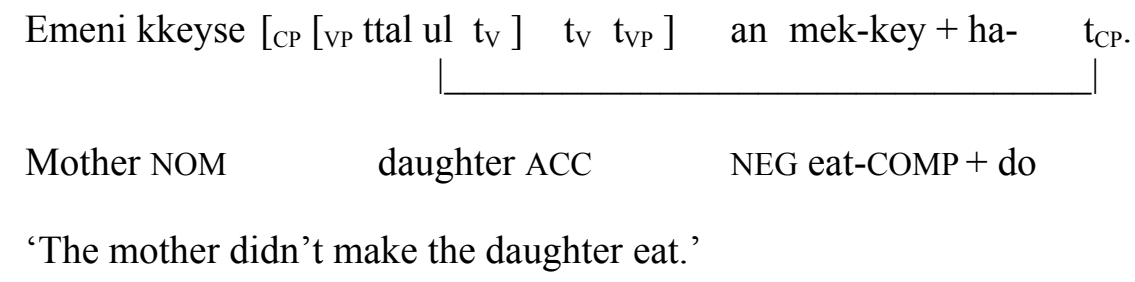

The analysis in (15-16) is based on the assumption that head raising and adjunction of the embedded verb to matrix causative $h a$ - is optional, thus predicting that the derivation in (16) could proceed without raising of embedded 'eat', producing the reverse order of the embedded verb and negative an. This is indeed the case (17); as predicted, (17) is unambiguously interpreted with matrix scope for negation.

Emeni kkeyse ttal ul mek-key an ha-si-ess-ta.

mother NOM daughter ACC eat-COMP NEG do-HON-PAST-INDIC

'The mother didn't make the daughter eat.'

The unavailability of matrix scope for negation in (14), where the embedded subject (causee) is marked with nominative case, can be accounted for by applying the generalization expressed by Baker's (1988) Government Transparency Corollary. The GTC permits a raised head to inherit the case assigning properties of the $\mathrm{X}^{0}$ category it raises and adjoins to. In (16), the embedded verb raises through Infl in the embedded clause to adjoin to matrix $h a$ - 'do'. Under the GTC, embedded Infl (more precisely, the trace $\left.\mathrm{t}_{\mathrm{V}+\mathrm{Infl}}\right)$ thus inherits the ability to assign accusative case. However when embedded Infl assigns nominative case, as in (14), the embedded verb has not raised. In such cases the only available derivation is the non head-raising one in (15), associated with embedded scope of negation. ${ }^{11}$

11 The Government Transparency Corollary (or its successor) cannot account for all instances of accusative case assignment to the embedded causee in periphrastic causatives. As we see in (18-19) below, accusative case may be assigned to the causee even when raising of the embedded verb is blocked. Lee (1992) argues 
More generally, the analysis in (15-16) predicts that if verb raising is blocked, embedded scope of negation must result. Verb raising in the periphrastic causative construction is blocked by insertion of an association with focus particle between $h a$ - and its complement, as noted by J.-S. Lee (1992):

Emeni kkeyse ttal ul an mek-key to ha-si-ess-ta.

mother NOM daughter ACC NEG eat-COMPalso do-HON-PAST-INDIC

'The mother also made the daughter not eat.'

Emeni kkeyse ttal ul an mek-key kkaci ha-si-ess-ta.

mother NOM daughter ACC NEG eat-COMP even do-HON-PAST-INDIC

'The mother even made the daughter not eat.'

As predicted, (18) and (19) have unambiguous embedded scope for negation.

Bratt (1993), working with an HPSG framework, accounts for the contrast in (13-14) by claiming that the periphrastic causatives with an accusative marked causee are monoclausal, while the same causatives with a nominative marked causee are biclausal. In the monoclausal case (13), the embedded verb and causative $h a$ - form a compound verb; negative an may attach either to the entire compound, resulting in matrix scope, or to the first verb in the compound, resulting in embedded scope. In the biclausal case (14), negative an preceding the embedded verb must be in the embedded clause.

Examples like (18-19) show that even with an accusative-marked causee, the embedded verb and the matrix causative verb cannot always be analyzed as a compound verb. However the problem posed by the periphrastic causative facts for a movement-based analysis based on a left-branching tree such as (5) is even more severe.

that accusative case can be assigned to the causee under a mechanism of Exceptional Case Marking. Lee's mechanism cannot explain the matrix scope interpretation of negation in (10), but it is possible that ECM is responsible for accusative case assignment to the causee in other contexts, when verb raising does not occur and only an embedded interpretation is available for negation. 
(20)

$(=17)$

IP

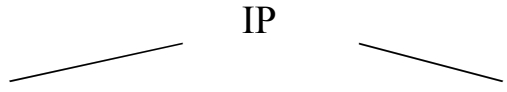

DP

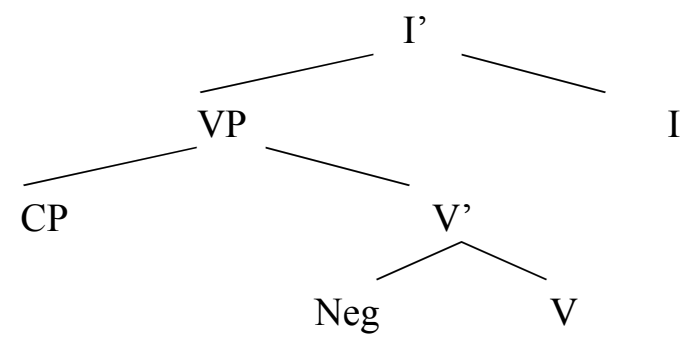

Emeni kkeyse ttal ul mek-key an ha -si-ess-ta.

mother NOM daughter ACC NEG eat-COMP do-HON-PAST-INDIC

'The mother didn't make the daughter eat.'

(20) shows negative $a n$ in the sister-of-V position of (5). This representation accounts for the matrix interpretation of an in (17). But it is unclear how to derive (13), where an precedes the embedded verb, on the matrix interpretation of $a$. A derivation where the embedded verb mek- 'eat' in (20) incorporates into causative $h a$ - would run counter to the generalization that incorporation occurs from complement, not from specifier position. Alternatively, an might be analyzed as a $\left(\mathrm{V}^{0}\right)$ internal prefix rather than a complement of V. Incorporation of the embedded verb would then take the form of infixation from complement position, as in (21):

(21)

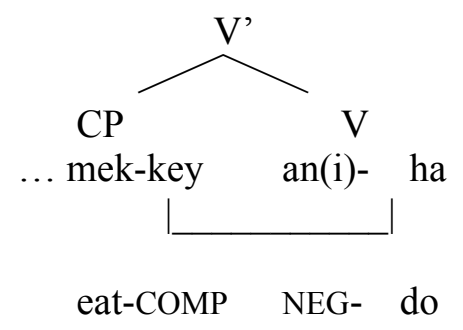

However such an account would have to explain why the raised verb is infixed after an, in a language which otherwise lacks infixation.

In general, the ability of negative an to take matrix scope in a context like (13), where it is preceded by the entire complement clause except for the complement verb, strongly suggests that Korean has both a mechanism of complement raising past a negative specifier and a mechanism of verb-to-verb raising. 


\subsection{Negative imperatives in earlier Japanese}

In Old and Early Middle Japanese, the uninflected negative imperative particle na.appears in two positions: the immediate preverbal position in (1b), and clause final position as in the second line of (22):

$$
\begin{aligned}
& \mathrm{Me}_{2} \text { gusi mo na mi } \mathrm{so}_{2} / \mathrm{ko}_{2} \mathrm{to}_{2} \text { mo to }{ }_{2} \text { gam-u na (Man'yôshîu 1759) } \\
& \text { worry too NEG see PRT deed too blame-CONCLUSIVE NEG } \\
& \text { 'Don't pity me / Don't blame me.' }
\end{aligned}
$$

Only the latter, clause final pattern survives in modern Tokyo Japanese. ${ }^{12}$ Clearly it is desirable to relate these two occurrences of the uninflected particle $n a$, both of which have the same negative imperative function. The key to relating them has to do with the shape of the lexical verb. In the preverbal pattern of (1b), the verb appears in a compound form, either the continuative stem pattern in (1b), or for the two irregular verbs $k u$ 'come' and $s u$ 'do' (23), the irrealis stem. The irrealis stem is normally a bound form, while the continuative is the normal stem for forming verb-verb compounds. A further characteristic of the preverbal pattern is that the lexical verb typically (although not always: see (24)) appears immediately before the etymologically obscure clause-final particle $\mathrm{SO}_{2}$ or $\mathrm{SO}_{2} \mathrm{ne}$.

Iza ko domo tapa waza na se $\quad$ so $_{2} \cdot\left(\right.$ Man'yôsh $\hat{u} 4487,8^{\text {th }}$ c.) heychildren foolish trick NEG do.IRREALIS PRT

'Hey kids, don’t try any foolish tricks.'

(24) Titi papa mo upe pa na sakari-i (Man'yôshîu 4487, $8^{\text {th }}$ c.) father mother too me TOPIC NEG depart-CONTINUATIVE 'Father, mother, don't leave me.'

12 Maeda's (1977: 39-40) description of the Osaka negative imperative V-CONTINUATIVE na (e.g. iki na, 'Don't go) suggests that it is the successor to the earlier preverbal negative imperative pattern. 
In contrast, in the postverbal pattern, the lexical verb always occurs in a finite (nonpast) form, either the conclusive form as in (22), or the adnominal (subordinate) form in the case of the verb "be" and its derivatives. These two are the normal forms for clausal subordination, the conclusive for subordination under the complementizer $\mathrm{to}_{2}$ 'that' and certain modals, the adnominal for participial subordinate forms.

The appearance of compound forms in the preverbal negative imperative pattern and subordinate forms in the postverbal pattern suggests that verb raising and adjunction takes place in the former pattern and that clausal complementation without verb raising takes place in the latter. This is exactly the difference we proposed for pre- and postverbal negation in Korean in 1.1. The occurrence of the particle $\mathrm{SO}_{2}$ immediately after the verb in the preverbal pattern further support the hypothesis that uninflected na occupies a specifier position in this pattern. The derivation of (1b) thus proceeds as in (25), parallel to (6):

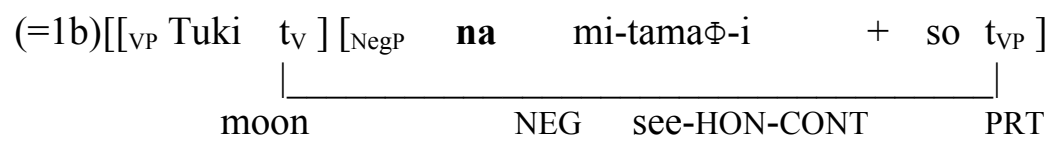

'Please don't look at the moon!'

In the preverbal pattern, in contrast, the lexical verb remains in its expected shape inside a complement clause. It is difficult to determine in this pattern whether $n a$ occupies a head or specifier position, but in either case, the surface word order and the inflectional form of the verb are accounted for by raising the projection containing the verb past $n a$, parallel to (7).

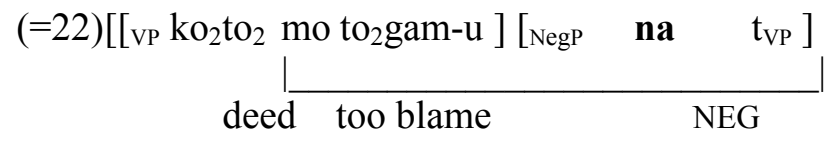

'Don't blame me.'

In this section we have seen that the inflectional forms of the verbs in the two negative imperative patterns of earlier Japanese support the two derivations for pre- and postverbal negation proposed in 1.1.

\subsection{Languages with SNegOV}

As noted in 1.1, Dryer (1998) lists six languages with SNegOV order: Yaqui (Aztec-Tanoan), Bambara, Mandinka, and Vai (Mande, Niger-Kordofanian), and Berta and Songhai (Nilo-Saharan) (1988:123). Of 
these six, the two Nilo-Saharan languages are actually SVO (Triulzi, Dafallah, and Bender 1976; Prost 1956).

However the three Mande languages listed by Dryer do indeed attest the order SNegOV, as shown in the Bambara example in (27):
À té
jége sàn.
(Bambara; Anschütz 1989: 48)

3S NEG.IMPERF fish buy

“S/he isn't buying fish.'

Thus in these languages, negation might superficially appear to occupy the predicted position for a specifier (or adjunct) negator on a symmetric left-branching picture of verb-final syntax, as in (28):

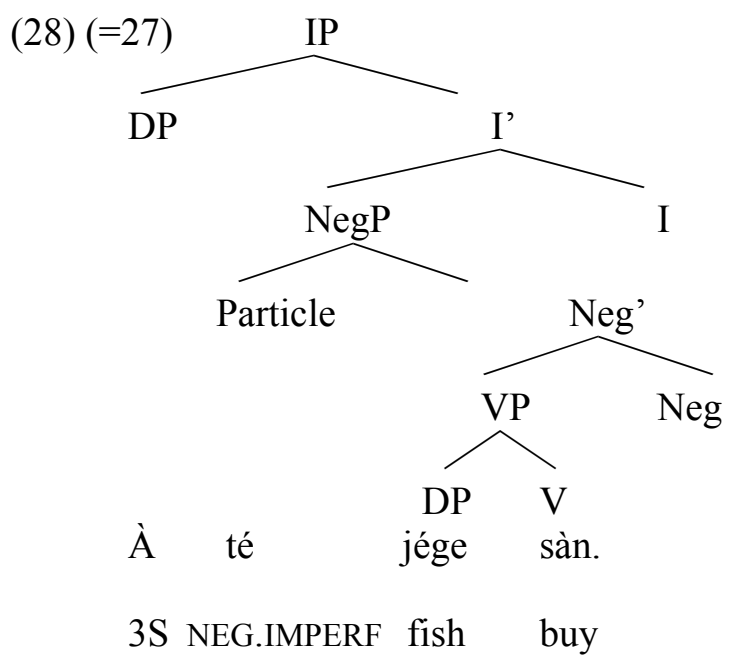

In 1.1, I argued that the SONegV pattern was the counterpart in VO languages to patterns involving a specifier or adjunct negator such as French pas in VO languages. But the preponderance of SONegV languages over SNegOV is, after all, only statistical. If it could be shown that (28) is the correct representation for the SNegOV pattern, we would be forced to recognize it as the true counterpart of pastype negation in OV languages.

In fact (28) is not an adequate representation for the Mande SNegOV languages listed by Dryer. As Koopman (1992) shows in her study of Bambara, the basic word order is Subject - Infl -Object - Verb non-casemarked Complement. Koopman shows that OV (and NP-P, NP-N, NP-Infl) order in Bambara is 
derived by movement of an NP complement to the left of its governing head for case purposes. Thus the surface order in (27) is derived by movement of the subject and object NPs, as shown in (29).

$$
\begin{aligned}
& \text { [IP À }\left[\mathrm{I} \text {, bé }\left[\mathrm{vP}_{\mathrm{A}} \mathrm{t}_{\mathrm{A}} \text { jége sàn } \mathrm{t}_{\mathrm{jege}}\right]\right. \text { ]] ] (Anschütz 1989: 48; structure from } \\
& \text { 3S IMPERF fish buy Koopman 1992: 558) }
\end{aligned}
$$

'S/he is buying a fish."

Most crucially for our purposes, Koopman analyzes negators as Infl elements. Each of the tense/aspect/mood indicators that appears in the position of Infl in (29) has a negative counterpart which appears in exactly the same position (and with which it is therefore in complementary distribution). Thus the negative counterpart of (29) is (30), with negative imperfective té in Infl:

$$
\begin{aligned}
& \text { (30) }(=27)\left[\text { IP } \grave{A}\left[\mathrm{I} \text { té }\left[\mathrm{vP}_{\mathrm{A}} \text { jége sàn } \mathrm{t}_{\text {jege }}\right]\right]\right] \\
& \text { 3S NEG.MPERF fish buy }
\end{aligned}
$$

'S/he is not buying a fish.'

The clause structure in (29-30) provides an immediate explanation for why the surface order of negation in Bambara is SNegOV rather than SONegV. We derived SONegV order by raising the verb to the head of the projection containing negation, and moving the remnant VP to the left past negation. But in Bambara, neither the verb nor the verb phrase move to the left of negation. More generally, we associated SONegV order with movement of VP to the left of Infl; clearly Bambara does not move VP to the left of Infl. This contrast suggests the following typological generalizations:

$$
\mathrm{SONegV} \text { is restricted to } \mathrm{OV}-\mathrm{Infl} \text { languages. }
$$

SNegOV is restricted to Infl - OV languages.

Note that (32) is not predicted by the non-derived left branching structure in (28) at all. This structure predicts that a specifier/adjunct negator should be able to appear to the left of the object in an OV language with clause-final Infl. 
Mandinka and Vai show the same complementarity between affirmative and negative tense-aspect-mood markers as Bambara. All occur before the VP, as in Bambara. The Mandinka examples below are from Wilson $(2000 / 2001)$ :

a. Siisewo ye kiloo laa.

chicken INFL egg lay

'The chicken laid an egg.'

b. Siisewo man kiloo laa.

chicken INFL.NEG egg lay

'The chicken didn't lay an egg.'

(34) a. Asi taa suu.

he INFL go home

'He is to go home.'

b. Akana taa suu.

he INFL.NEG go home

'He isn't to go home.'

Dryer's remaining example of an SNegOV language is the Uto-Tanoan (Tara-Cáhitic) language Yaqui. Yaqui also attests surface SNegOV order:

‘Emé’ekáa hunúen ‘án-nee. ～～(Dedrick and Casad 1999: 56)

you-PL NEG thus do-fut

'You must not do that.' (Do it rather in some other way.)

On the basis of data like (35), Lindenfeld (1973) posits a rule that inserts the negator kaa directly after the subject. Once again, Yaqui might appear to attest the left-branching symmetric structure in (28) that we ultimately rejected for Mande; in the Yaqui case, kaa would occupy the specifier of a left branching Neg P.

However Dedrick and Casad show that káa and its imperative counterpart kát do not occupy a position directly to the right of the subject. They show that Yaqui is a language with second position clitics. Clitics 
include subject pronouns, emphatic and dubitative particles, and negative $k a a$. Clitics are preceded by a topicalized phrase, although as in other clitic-second languages there is some leakage to this phenomenon: in certain sentence patterns clitics may appear in initial position in others, some other item (such as certain adverbs) may precede the clitic string in addition to the topic. Thus in contrast to (35), which topicalizes 'you' and focuses 'thus', (36) focuses 'you':

Káa 'emé’e hunúen' án-nee.

(Dedrick and Casad 1999: 56)

NEG you-PL thus do-FUT

'You must not do that.' (Others may.)

(37) shows negative imperative kát preceded by an adjunct clause and followed by the clitic form of the second person pronoun. Note that negation precedes pronominal clitics:

Née muku-k-o kát =e'em hi’osia-ta née sewá-tua. (Dedrick and Casad 1999: 59)

I die-PERF-when NEG=you:PL paper-ACC me flower-cause

'When I die, don't put paper flowers on me.'

These facts show that negation in Yaqui is not the specifier of a left branching projection between the subject and the VP, but rather a second position clitic. Its surface position appears to be the head of the projection that hosts topics.

Summarizing the results of this section, even among the small number of languages in Dryer's sample that superficially attest the order Subject - Negation - Object - Verb, none appear actually to attest a structure corresponding to (28), where the preverbal negative particle occupies the a specifier (or adjunct) position above VP. This result is totally unexpected on a conventional, left-branching picture the syntax of head-final languages. As we have seen, however, it is readily explained by an account which derives head final order by raising the verb to the left and moving the remnant VP past it.

\subsection{Pre-verbal auxiliaries in OV languages}


Dryer (1992) observes that tense/aspect markers display the same dual positioning as negative markers in OV languages. When the tense/aspect marker is a particle (specifically, when it lacks inflection), the marker tends to precede the verb, although some cases of SOVTense/Apect also occur. Dryer shows 18 instances of SOTense/AspectVerb and 6 instances of SOVTense/Aspect in his genetically and areally balanced sample (1991: 99). More importantly, the generalization is almost categorical in the case of inflected Tense/Aspect auxiliaries: these tend overwhelmingly to follow the verb in OV languages. Dryer lists 36 examples of SOVAux and 3 examples of SOAuxV (1992: 100). Although Dryer does not specify which languages in his sample are SOAuxV, all three are in Africa. As six Mande languages (Susu, Vai, Mandinka, Gambian Mandinka, Bambara, Mende), are in Dryer's sample, it seems likely that these are the source of the $\mathrm{SOAuxV}$ pattern. Although the pattern in question in Mande languages is in fact $\mathrm{SAuxOV}$, Dryer does not distinguish preverbal and immediate preverbal position in his discussion. Needless to say, Koopman's (1992) analysis of Bambara accounts for SAuxOV order in these cases.

Further research is required to fully explore the range of tense, aspect, and mood markers that occur asx preverbal particles in OV languages. In the remainder of this paper, I will explore three such particles in Japanesese and Korean.

\subsection{Preverbal $e$ 'can' and ari 'be..ing' in Earlier Japanese}

Premodern Japanese had two preverbal modal/aspectual markers, $e$ 'can', expressing (nondeontic, nonepistemic) possibility; i.e. ability, and ari, expressing ongoing action. I label the former 'potential' and the latter 'progressive' here. Both $e$ and ari are identical to the continuative forms of the corresponding verbs, $u$ 'be able to' and ari 'exist' respectively.

Sa-wo-pune no $_{2}$ e yuk-i te pat-e-mu. (Man'yôshî 2091, ${ }^{\text {th }}$ c.)

PREF-small-boat GEN POT go-ing stop-IRR-CONJECTURE

'The small boat will likely be able to go and dock.'

$\mathrm{Sima} \mathrm{no}_{2}$ sakizaki ari tat-er-u

panatatibana. 
island GEN capes $\quad$ PROG stand-IMPERF-ADNOM flower

(Man'yôshû 3239, $8^{\text {th }}$ c.)

'the flowers that are standing on the capes of the islands'

Already predominantly in Old Japanese, and exclusively in later stages of the language, $e$ occurs in negative potential sentences.

(40) Sato to $\prod$ o-ki $\prod$ a e tugeyar-a-z-u.

(Makura no sôshi, 995)

home far-ADNOM TOP POT word-send-IRR-NEG-CONCLUSIVE

'We were unable to send word to those whose homes were far-off.'

Two properties of preverbal $e$ and ari are relevant to our concerns. First, both of these items correspond

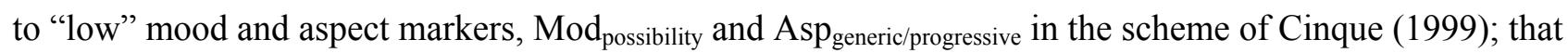
is, they are positioned under Tense. Second, the interpretation of examples like (40) shows that preverbal $e$ always takes scope under negation.

Both of these properties are accounted for if assume that $e$ and ari are specifiers. that they are specifiers. The verb moves to the head of the projections containing $e$ and ari; the remnant $\mathrm{Vp}$ then moves to the left of these specifiers. In a negative sentence such as (40), the verb moves past the modal projection containing $e$ to adjoin to the head of $\mathrm{NegP}, z$-. The complement of $\mathrm{NegP}$ then moves past $\mathrm{V}+\mathrm{Neg}$, parallel to (8). This is shown in (41), omitting material in the remnant VP complement of Mod:

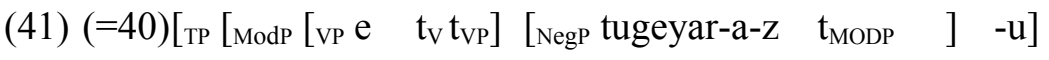

POT $\quad$ word-send-IRR-NEG -CONCLUSIVE

The low scope of $e$ is consistent with this derivation, where it originates in a projection c-commanded by negation.

\subsection{Preverbal cal 'well' in Korean}

In the $§ 2.2$ we sketched a derivation of preverbal modal/aspect markers in premodern Japanese, accounting for their type ("low") and scope (lower than negation). Korean lacks preverbal aspect or modal 
markers, but it has a preverbal adverb corresponding to another "low" functional head in Cinque's 1999 system: $c a l$ 'well'. 13

As observed by many authors, $c a l$ is restricted to immediate preverbal position. The following examples are from J.-H. Lee (1993: 434).

a. Chelswu nun sayngsenhoy lul cal mek-nun-ta.

Chelswu TOP raw fish ACC well eat-PRES-INDIC

'Chelswu often eats raw fish.'

b. *Chelswu nun cal sayngsenhoy lul mek-nun-ta.

Chelswu TOP well raw fish ACC eat-PRES-INDIC

'Chelswu often eats raw fish.'

The distribution of cal can be accounted for in the same fashion as the premodern Japanese mood/aspect markers discussed in the previous section. The verb moves to the head of the projection hosting cal in its specifier; the remnant then moves to the left of cal.

Korean however contains another possibility not present in modern Japanese: the preverbal negation pattern of (6). We see in (43) that cal must precede preverbal an or mos:

a. Mica ka hakkyo ey cal mos/an ka-ss-ta.

Mica NOM school to well cannot/NEG go-PAST-INDIC

'Mica didn't/couldn't often go to school.'

13 Cal corresponds to 'well' in with statives, accomplishment, and achievement, verbs, 'often' with activity verbs. Both correspond to relatively low functional heads in Cinque's (1999) system: Voice in the case of 'well', frequentative in the case of 'often'. As my examples in this section involve an activity interpretation, I label the projection hosting cal FreqP. 
b. ${ }^{*}$ Mica ka hakkyo ey mos/an cal ka-ss-ta.

Mica NOM school to cannot/NEG well go-PAST-INDIC

The ordering in (43) is predicted by the derivation of preverbal negation in (6) and our account of potential $e$ and negation in premodern Japanese sketched in the previous section. The projection containing cal is generated as a complement of Neg. The verb moves through the head of the projection containing cal to the head of NegP. The remnant VP moves to the left of cal; finally the larger remnant containing VP and cal moves to the left of negation.

While the facts concerning preverbal mood/aspect markers discussed in the previous section are mildly problematic for a base-generated left-branching representation of Japanese phrase structure (as with preverbal negation, they require generating the mood or aspect marker in the VP complement position), the relative positioning of $\mathrm{cal}$ and mos/an is more problematic. Consider an analysis where $c a l$ and $a n / m o s$ are generated as iterated sisters of the verbal projection:

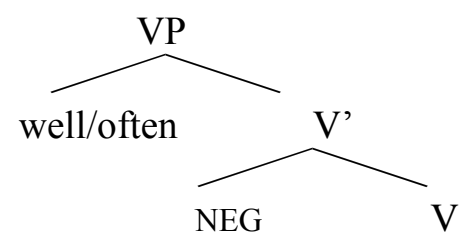

The structure in (44), if it makes any prediction about the relative scope of 'well/often' and negation, predicts that the former should take scope over the latter. As we have seen, this is exactly the wrong prediction. The appropriate descriptive generalization would appear to be (45):

(45) Functional items immediately preceding or following the verb in Verb-Infl languages take scope from right (higher) to left (lower).

While a base-generated left-branching analysis of Verb-Infl languages can handle the generalization in (45) for items that follow the verb, it appears to be unable to handle the generalization for items that precede the verb.

\subsection{Conclusion}


One of the major accomplishments of Dryer (1992) is to show that noninflected negative and tense/aspect/modal particles are as likely - in fact more likely - to precede the verb as follow it in V-final languages. As Dryer argues, these facts militate against a uniform treament of these items as "verbpatterners", that is, as heads. The alternative is to treat such preverbal functional elements as specifiers. As we have seen, however, this move alone is insufficient: on a base-generated left-branching analysis of verbfinal syntax, both their position (immediately before the verb) and their scope (always low) is unexpected. I have argued that these typological generalizations support a view where V-Infl order is derived, and that the relevant derivations involve both verb and remnant movement. 


\section{References}

Ahn, Hee-Don. 1991. Light Verbs, VP-Movement, Negation, and Clausal Architecture in Korean and English. Ph.D dissertation, University of Wisconsin, Madison.

Anschütz, Susanne. 1989. Aktantenfunktionen und Thema-Rhema im Bambara. Heidelberg: Julius Groos Verlag.

Baker, Mark. 1988. Incorporation: A Theory of Grammatical Function Changing. Chicago: University of Chicago Press.

Bratt, Elizabeth Owen. 1993. "Clause Structure and Case marking in Korean Causatives.” In Kuno, S., I.-K. Lee, Y.-S. Kang, Y. Kim, J. Maling, \& J. Whitman (eds.) Harvard Studies in Korean Linguistics V, pp. 241-252.

Cinque, Guglielmo. 1999. Adverbs and Functional Heads: A Cross-Linguistic Perspective. Oxford and New

York: Oxford University Press.

Choi, K. (1991) A Theory of Syntactic X0 Subcategorization. Ph.D. dissertation, University of Washington, Seattle.

Dahl, Östen. (1979) “Typology of Sentence Negation,” Linguistics 17: 79-106.

Dedrick, John and Casad, Eugene. 1999. Sonora Yaqui Language Structures. Tucson: University of Arizona Press.

Dryer, Matthew. 1988. "Universals of Negative Position,” in Hammond, M., E. Moravcsik \& J. Wirth (eds.) Studies in Syntactic Typology, 93-124. Amsterdam: John Benjamins.

1992. “The Greenbergian Word Order Correlations.” Language 68.1, 81-138. 
Hagstrom, Paul. 2000. "Phrasal Movement in Korean.” In Veselinova, L., Robinson, S,, and Antieau L. (eds.) MIT Working Papers 36, Proceedings of SCIL 9. Department of Linguistics, MIT.

Halle, Morris, and Alec Marantz. 1993. "Distributed Morphology and the Pieces of Inflection.” In Hale, Ken and Keyser, Samuel J. (eds.), The View from Building 20: Essays in Linguistics in Honor of Sylvain Bromberger. Cambridge: MIT Press.

Kayne, Richard. 1994. The Antisymmetry of Syntax. Cambridge: MIT Press.

Koopman, Hilda. 1992. "On the Absence of Case Chains in Bambara." Natural Language and Linguistic Theory 10.2, 555-594.

Lee, Chungmin and Whitman, John (eds.) 2000. Korean Syntax and Semantics. Papers from the LSA Institute Workshop, UC Santa Cruz, 1991. Seoul: Tahehaksa.

Lee, Jeong-Shik. 1992. Case Alternation in Korean: Case Minimality. Ph.D. dissertation, University of Connecticut.

Lee, Young-Suk. 1988. “The Korean Causative: A TAG Analysis.” Paper given at the $63^{\text {rd }}$ Annual Meeting of the Linguistic Society of America, New Orleans.

Lee, Jae-Hong. 1992. 'Postverbal Adverbs and Verb Movement in Korean,' in Clancy, P. (ed.) Proceedings of the Second Southern California Conference on Japanese and Korean Linguistics, 428-446. Stanford: CSLI.

Maeda, Isamu. 1979. Ôsaka ben. Asahi sensho 80. Tokyo: Asahi shinbunsha. 
Park, Kabyong. 1990. 'Negation, Verb Movement, and Light Verbs in Korean,' in E.-J. Baek (ed.) Papers from the Seventh International Conference on Korean Linguistics., 387-398. Toronto: University of Toronto Press.

Pollock, Jean-Yves. 1989. "Verb Movement, Universal Grammar and the Structure of IP.” Linguistic Inquiry

$20.3,365-424$.

Prost, R.P.A. 1965. La Langue Sonay et Ses Dialectes. Mémoires de l'Institut Français d'Afrique Noire, 47. Dakar: Ifan.

Rizzi, Luigi. 1997. “The Fine Structure of the Left Periphery.” In Haegemann, Liliane (ed.) Elements of Grammar, 281-338. Dordrecht: Kluwer.

Sakai, Hiromu. 1998. "Feature Checking and Morphological Merger.” In Silva, David (ed.), Japanese/Korean Linguistics 8, 189-208. Stanford: CSLI.

Sells, Peter. 1998. "Structural Relationships within Complex Predicates.” In Park, B.-S. and Yoon, James (eds.) The $11^{\text {th }}$ International Conference on Korean Linguistics. Seoul: Hanguk Publishing. Sells, Peter and Young-me Yu Cho. 1991/2000. “On the Distribution of X0 Elements in Korean.” Paper given at the Workshop on Korean Syntax and Semantics, Linguistic Society of America Summer Institute, University of California at Santa Cruz, 1991. Published in Lee and Whitman, John (2000).

Song, Seoul Choong. 1971. “A Note on Negation in Korean.” Linguistics 76, 59-76.

Triulzi, A.A., Fafallah, A.A., and Bender, M.L. 1976. "Berta.” In Bender, M. Lionel (ed.) The Non-Semitic Languages of Ethiopia. East Lansing: Michigan State University African Studies Center. 
Whitman, John. 1998. "Gojun to ku kôzô” (Word order and phrase structure). In Takezawa, Kôichi and Whitman, John, Nichieigo hikaku sensho, volume 9: Kaku to gojun to tôgo közô (Case, word order, and syntactic structure). Tokyo: Kenkyûsha, 1998. . 1995. "Apparent Discontinuities in the Acquisition of Verbal Morphology in Korean."

Paper

presented at the Daewoo Symposium on Child Acquisition of Korean, Seoul National University. Published as “Tongsa kuljeoreo seupteuk kwa paltal euy pulyeonsokseong” (Discontinuities in the acquisition of verbal inflection), in Cho, Sook-Hwan (ed.) 2000. Ingan eun eoneo lul eotteokhe seupteuk haneun ka (How do humans acquire language?), 173-192. Seoul: Akhanet. . 2001. “Kayne 1994: p. 143, fn. 3.” In G. Alexandrova \& O. Artunova (eds.), The Minimalist Parameter, 77-100. Amsterdam, John Benjamins.

Wilson, W.A.A. 2000/2001. “Creissel's Mandinka Grammar.” The Journal of West African Languages 28.2 109-124. 